\title{
Tumor renal en ectopia renal cruzada con fusión
}

\author{
C. Aguilera Tubet, J.I. Del Valle Schaan, B. Martín García, J.A. Portillo Martín, \\ J.L. Gutiérrez Baños, R. Ballestero Diego
}

Servicio de Urología. Hospital Universitario Marqués de Valdecilla. Santander.

Actas Urol Esp 2005; 29 (10): 993-996

\section{RESUMEN}

TUMOR RENAL EN ECTOPIA RENAL CRUZADA CON FUSIÓN

La ectopia renal cruzada es una anomalía renal congénita poco frecuente y en la mayoría de los casos se presenta con fusión de ambos riñones. Estos pacientes suelen permanecer asintomáticos hasta la $4^{\text {a }}-5^{\underline{a}}$ década y desarrollar entonces problemas de infecciones urinarias, litiasis, masa abdominal o dolor que simula un problema gastrointestinal. Presentamos el caso de un tumor de células renales aparecido en un paciente con ectopia renal cruzada con fusión, descubierto en un TAC realizado por sospecha de patología gastrointestinal.

Palabras clave: Ectopia renal cruzada con fusión. Tumor de células renales. Malformaciones congénitas.

\section{ABSTRACT}

\section{RENAL CELL CARCINOMA IN CROSSED FUSED RENAL ECTOPIA}

Crossed renal ectopia its a rare congenital malformation and in most cases it presents with fusion of both kidneys. Patients should be asynptomatic until $4^{\mathrm{a}}-5^{\mathrm{a}}$ decade and at that time they unfold urinary infection, urolithiasis, abdominal mass or pain that simulates a gastric disease. We report a case of renal cell carcinoma in a patient with crossed fused renal ectopia, showed in a Scan that was performed for gastric disease suspicion.

Keywords: Crossed fussed renal ectopia. Renal cell carcinoma. Congenital malformations.

$\mathrm{L}$ a localización anómala del riñón en el espacio retroperitoneal se denomina ectopia renal. La ectopia renal congénita representa un fallo en el desarrollo embriológico normal del sistema genitourinario en que los riñones ascienden hasta ocupar su localización normal en el retroperitoneo. La ectopia renal cruzada con o sin fusión es una rara entidad con una incidencia de uno de cada 7.500 autopsias $^{1}$. El termino ectopia renal cruzada con fusión implica el que uno de los dos riñones cruce la línea media o que ambos se aproximen lo suficiente como para fusionarse. La incidencia de ectopia renal cruzada se estima en un caso de cada 700-1.000 2 nacimientos.

Presentamos el caso de un carcinoma de células renales aparecido en un riñón con una ectopia renal cruzada con fusión.

\section{CASO CLÍNICO}

Paciente que acude por primera vez a la consulta de Urología por un episodio de cólico nefrítico derecho a los 55 años. Como antecedentes personales destaca una diabetes tipo II controlada con dieta, una neumonía a los 30 años y apendicectomía a los 18 años. El paciente cuenta una historia de molestias sordas en fosa renal derecha, continuas, de unos 20 años de evolución.

Entre las pruebas diagnósticas realizadas se encuentra una ecografía urológica que es informada como disposición baja de los riñones en fosa iliaca derecha, apareciendo fusionados, hallazgos compatibles con ectopia renal cruzada con fusión. Ante los hallazgos se procede a la realización de una UIV, que identifica ambos riñones 
en la fosa lumbar derecha, con rotación marcada de sus ejes y con integridad completa de los sistemas colectores (Fig.1 ), con desembocadura normal de ambos uréteres en la vejiga, provocando esto una ectopia renal cruzada.

Tres años después, el paciente es remitido desde la consulta de digestivo donde lo estudian por molestias digestivas. En un TAC realizado por este Servicio se observa una masa de $4,5 \mathrm{~cm}$ en el polo inferior del riñón ectópico, sin adenopatías (Fig. 2). Se decide la realización de una tumorectomía previa realización de arteriografia selectiva para estudio de la disposición de los vasos renales (Fig. 3). Durante el acto quirúrgico se procede a la identificación de los vasos renales y los uréteres de ambos riñones. Se observa la neoformación situada sobre el polo inferior del riñón ectópico, procediéndose a la realización de tumorectomía de la masa.

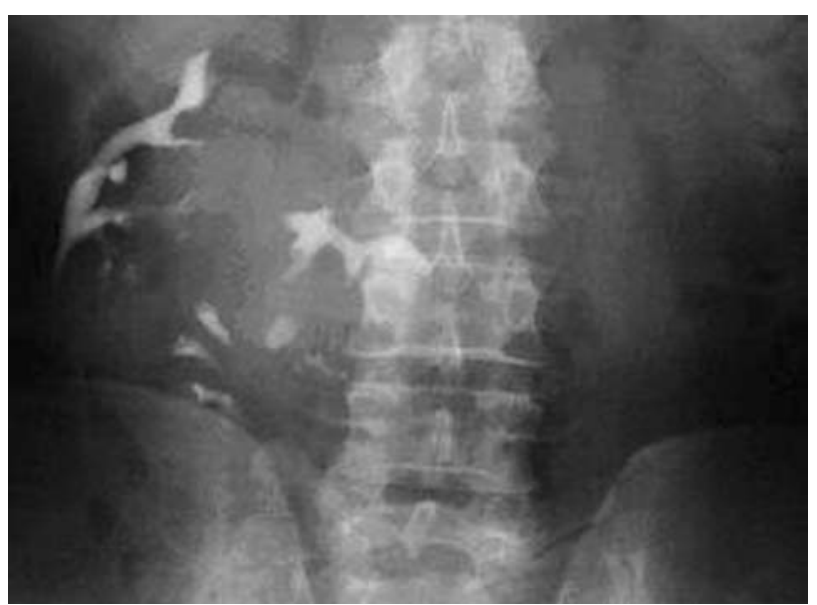

FIGURA 1

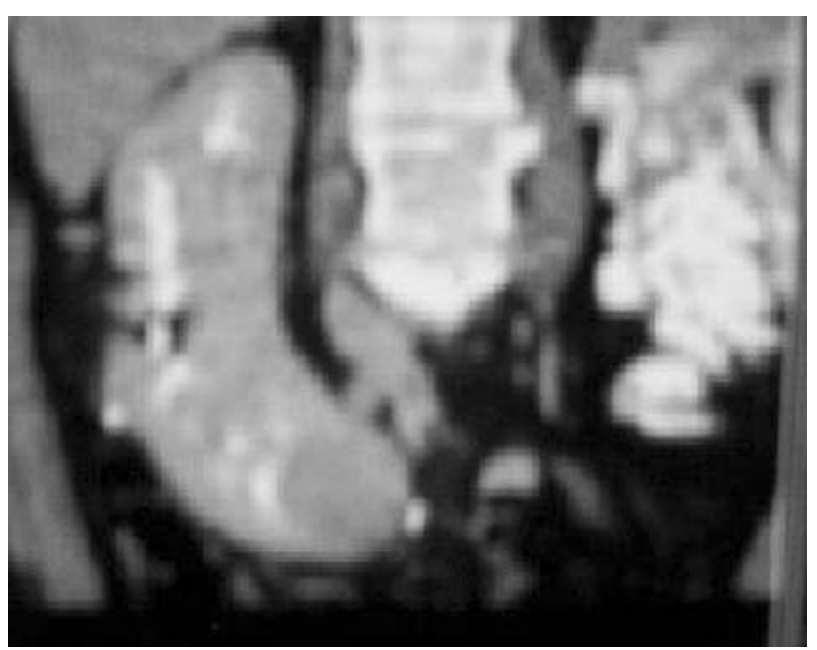

FIGURA 2

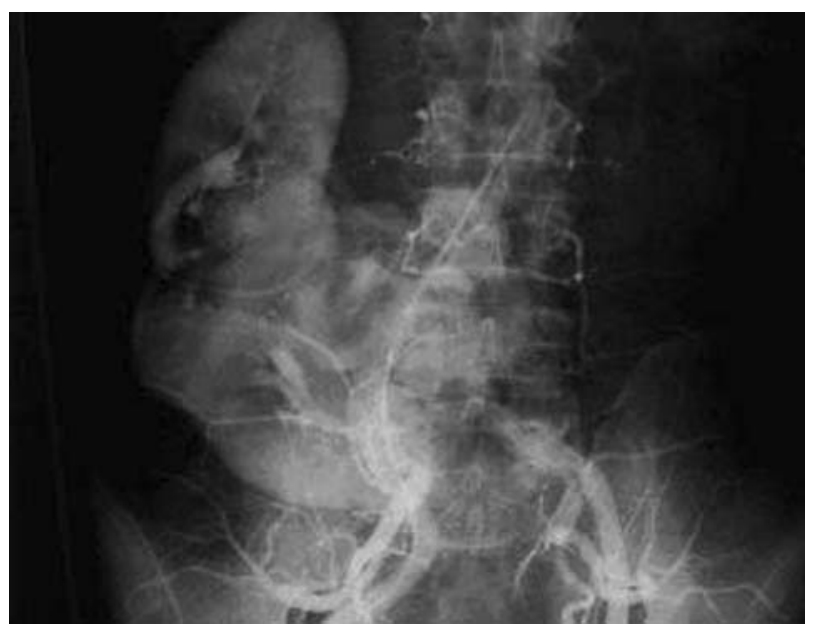

\section{FIGURA 3}

El estudio macroscópico de la pieza muestra una tumoración de 4,5 × 3,5 × $2 \mathrm{~cm}$ de forma ovoide y consistencia blanda. Al corte es de coloración blanquecina con zonas amarillentas y presenta una fina cápsula circundante. El estudio microscópico etiqueta la masa como un carcinoma de células renales de tipo no especial no papilar (células claras) grado 2 de Fuhrman de 4,5 cm de diámetro que respeta el borde quirúrgico. La toma de biopsias intraoperatorias del lecho tumoral no evidenció presencia de malignidad.

En la actualidad el paciente está asintomático y libre de recidiva tumoral o metástasis tras 6 años de seguimiento mediante TAC seriados (Fig. 4).

\section{DISCUSIÓN}

Cuando un riñón ocupa una situación distinta a la habitual en el retroperitoneo y además

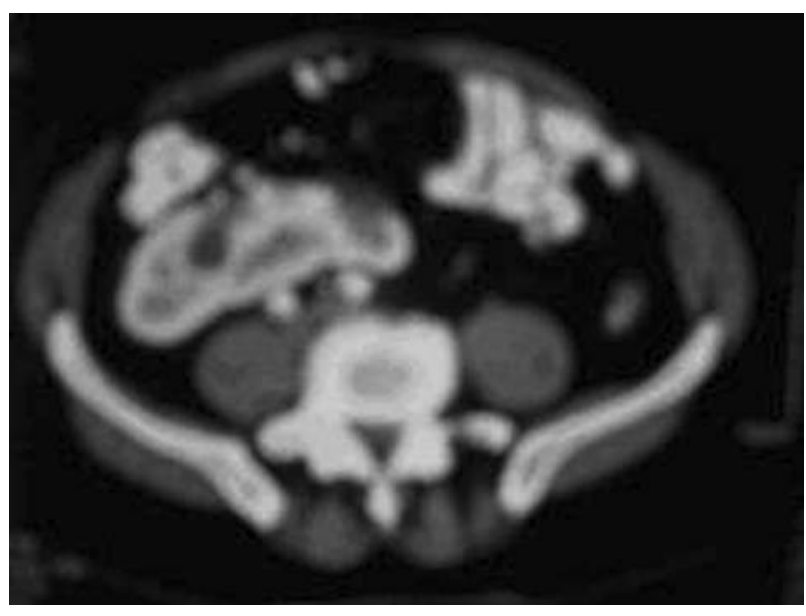

FIGURA 4 
cruza la línea media ocupando el lado opuesto de su inserción en la vejiga, se denomina ectopia renal cruzada. McDonald y McClellan ${ }^{3}$ en 1957 lo clasificaron en cuatro grupos dependiendo del tipo de ectopia; ectopia cruzada con fusión, ectopia cruzada sin fusión, ectopia cruzada solitaria y ectopia cruzada bilateral. La ectopia renal cruzada con fusión ha sido dividida a su vez en: riñón fusionado unilateral inferior, riñón sigmoide o en $\mathrm{S}$, riñón en $\mathrm{L}$, riñón en Torta, riñón en disco y riñón fusionado unilateral superior.

La fusión ocurre en el 90\% de los riñones ectópicos. Abeshouse recoge 500 casos de ectopia renal cruzada de los que solamente un 10\% corresponden a ectopia renal cruzada sin fusión y el resto a ectopias con fusión ${ }^{4}$. La forma mas frecuente ocurre cuando la fusión se produce entre el polo inferior del riñón homolateral con el polo superior del riñón cruzado, como ocurre en nuestro caso. Hay una ligera prevalencia en el hombre y un predominio de cruzamiento hacia el lado derecho.

La fusión se produce durante la semana $4^{\mathrm{a}} \mathrm{y}$ $5^{\underline{a}}$ del desarrollo embriológico. No se conocen con exactitud los mecanismos por los que ocurre. Perlmutter ${ }^{5}$ recopila las teorías emitidas por distintos autores: la primera teoría afirma que sería el resultado de una situación anómala de las arterias umbilicales que impedirían la migración cefálica de la unidad renal, encontrándose obligada a desplazarse al lado opuesto de la línea media. Otros autores sugieren la idea de un desplazamiento lateral de la yema ureteral, induciendo en el lado contralateral la formación de una unidad renal al entrar en contacto con la masa metanefrógena. También se han implicado factores teratógenos al estar asociado a malformaciones del sistema genitourinario y de otros sistemas ${ }^{6}$. Se suele asociar a malrotación renal y anomalías de la vascularización renal, pudiendo nacer los vasos de la aorta, de la arteria sacra media o de las arterias iliacas.

Los pacientes suelen permanecer asintomáticos hasta la $4^{\underline{a}}$ o $5^{\underline{a}}$ década de la vida en que debutan con infección urinaria, litiasis, masa abdominal o dolor simulando un problema gastrointestinal. Se piensa que la situación anómala del riñón dificulta el drenaje normal de la orina favoreciendo esto la aparición de infecciones urinarias y la formación de cálculos.
El diagnóstico se realiza de forma habitual mediante ecografía realizada por otra causa en que se pone en evidencia la ausencia de una unidad renal en su situación normal hallando esta después al otro lado de la línea media ${ }^{7,8}$. La técnica más adecuada para caracterizar el tipo de ectopia es la urografía endovenosa ${ }^{9}$. En una cistoscopia, los meatos ureterales se observan en su situación normotópica. En el caso que nos ocupa, el TAC parece la mejor técnica no para identificar la ectopia renal sino para la identificación del tumor renal. La arteriografía selectiva era la técnica de elección para conocer la disposición de los vasos renales. Actualmente, con la existencia de Tac de última generación con la posibilidad de realizar una reconstrucción vascular en 3D, la arteriografía ha quedado desfasada.

En cuanto al pronóstico de estos pacientes, este suele ser favorable precisando control periódico y tratamiento en función de las complicaciones que vayan apareciendo. En el caso presentado se pudo realizar una tumorectomía, conservando el resto da la unidad renal.

Hemos encontrado referencias en la literatura de un caso de carcinoma de células transicionales en un riñón con una ectopia cruzada con fusión en que se realizo nefroureterectomía ${ }^{10}$, otro caso de ectopia renal cruzada diagnosticado a raíz de la aparición de una lesión ósea con diagnóstico anatomopatólogico de metástasis de carcinoma de células renales ${ }^{11}$ y un último caso de resección de un carcinoma de células renales en un riñón en $\mathrm{L}^{12}$.

\section{REFERENCIAS}

1. Siegel RL, Resenfeld DL, Lemain S. Complete regression of a multicystic kidney in the setting of renal crossed fused ectopia. J Clin Ultrasound 1992;20(7):466-469.

2. Pérez García FJ, Regadera Sejas FJ, Fernández Gómez JM, Rodríguez Martínez JJ, Rabade Rey CJ, San Martín Blanco. Disk kidney. Report of a case. Actas Urol Esp 1996;20(10): 907-911.

3. McDonald JH, McClellan DS. Crossed renal ectopia. Am J Surg 1957;93(6):995-1002.

4. Abeshouse BS.: Crossed ectopia with fusion: review of the literature and a report of four cases. Am J Surg 1947;73: 658-683.

5. Perlmutter A, Retik A, Bauer S. Anomalías del tracto urinario. En Campbell Urología de P. Walsh, R. Gittes, A. Perlmutter, S. Stamey (eds) Ed. Panamericana 1791 Buenos Aires 1988. 
6. Friedland GW, De Vries P. Renal ectopia and fusion. Embriologic basis. Urology 1975;5(5):698-706.

7. Goodman JD, Norton KI, Carr L, Yeh HC. Crossed fused renal ectopia: sonographic diagnosis. Urol Radiol 1986;8(1):13-16.

8. Nussbaum AR, Hartman DS, Whitley N, Mccauley RG, Sanders RC. Multicystic dysplasia and crossed renal ectopia. AJR Am J Roentgenol 1987;149(2):407-410.

9. Muttarak M, Peh WC, Lerttumnongtum P. Clinics in diagnostic imaging. Crossed-fussed renal ectopia. Singapore Med J 2001;42(3):139-141.

10. Gur U, Yossepowitch O, Baniel J. Transitional cell carcinoma in a fused crossed ectopic kidney. Urology 2003; 62 (4):748.
11. Siegel HJ, Casillas MA. Crossed fused renal ectopia with metastasic renal cell carcinoma. Clin Nucl Med 2004; 29(11): 765-766.

12. Tsunoe H, Yasumasu T, Tanaka M, Kai N, Naito S. Resection of an L-shaped kidney with renal cell carcinoma using a microwavw tissue coagulator. Int J Urol 2001;8(8):459-462.

Dra. C. Aguilera Tubet

Paseo de Canalejas $11 \mathrm{D}^{\circ} \stackrel{\mathrm{O}}{\mathrm{H}}$

39004 Santander (Cantabria)

E-mail: car1677@hotmail.com

(Trabajo recibido el 29 de abril 2005) 